\title{
Servidor de Automação e Automação LEAN Para uma GTC mais otimizada
}

1. Servidor de automação - Integração de diversos protocolos em plataforma única compatível com as tecnologias web/IT

Durante muito tempo, os integradores e instaladores foram confrontados pelos diversos fabricantes de automação por desenvolvimentos que faziam com que os clientes finais ficassem cada vez mais presos às suas soluções proprietárias com softwares dedicados, redes dedicadas e drivers dedicados.

E o paradigma de uma instalação facilmente se torna num conjunto heterogéneo de diferentes soluções proprietárias como se de ilhas isoladas se tratassem ou com a necessidade de software SCADA com drivers e interfaces para todas essas soluções.

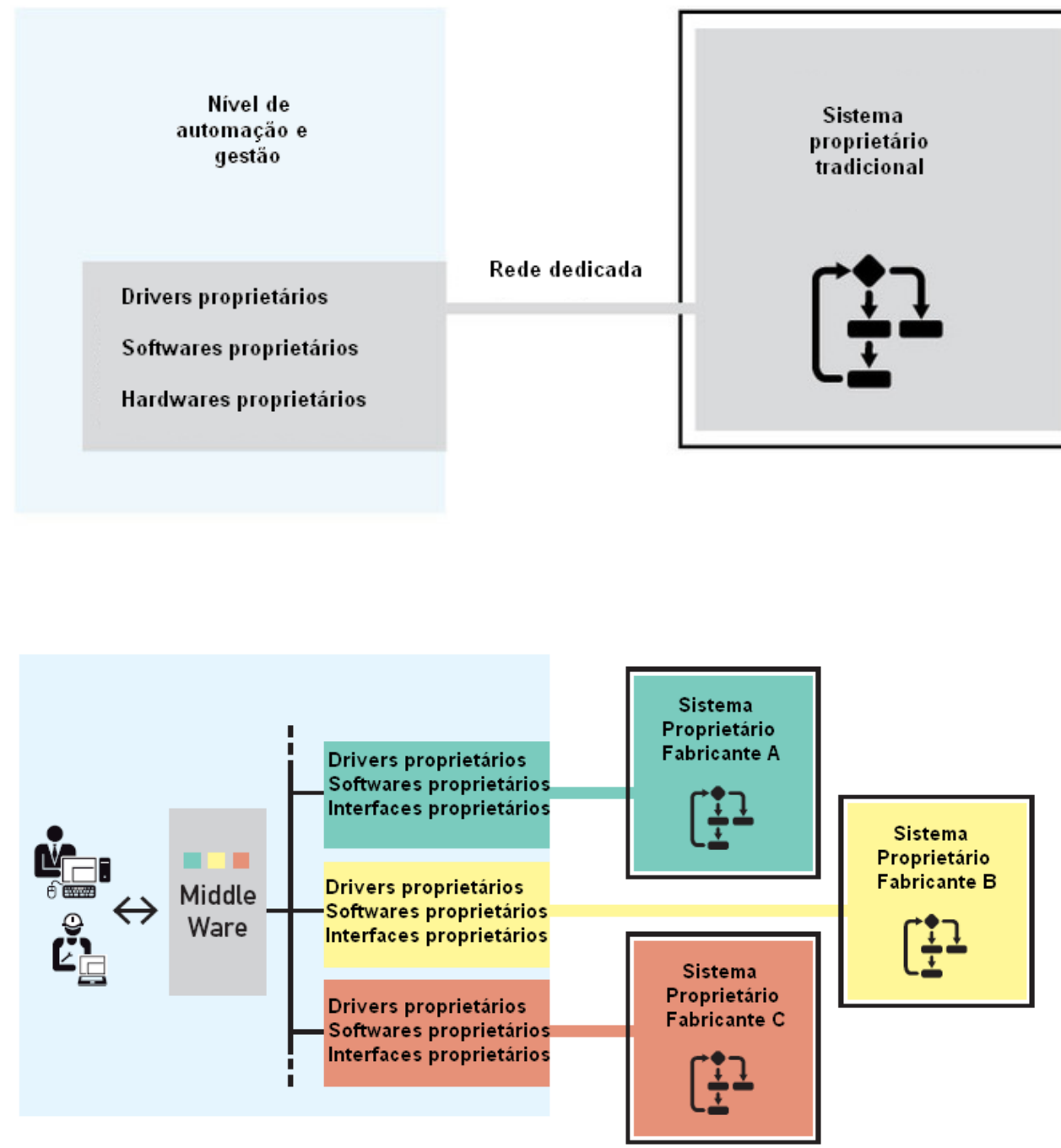


A alternativa a esse paradigma é o Servidor de Automação.

O Servidor de Automação pode ser um conceito relativamente novo na automação, mas é baseado em tecnologias já comprovadas e estabilizadas.

Sendo os autómatos da SAIA multiprotocolo, é possível um autómato funcionar como gateway para autómatos de outros fabricantes, garantindo desse modo a abertura para sistemas de automação normalmente proprietários.

É uma combinação de funcionalidades Web e IT com interfaces standard e universais que foram incorporados diretamente no autómato programável, permitindo ao utilizador um acesso aos recursos proprietários da unidade.
Servidor Web, servidor FTP, cliente SMTP e sistema de ficheiros estão localizados diretamente no autómato, sem a necessidade de aquisição de componentes externos adicionais.

Estas funcionalidades permitem ao utilizador, a partir do seu próprio ambiente de trabalho e usando ferramentas comuns como um browser Web, aceder diretamente ao autómato e ler e escrever dados.

O operador não precisa mais de comprar as tais ferramentas proprietárias dispendiosas; não precisa mais de interfaces proprietários e drivers do fabricante; nem tem mais problemas com dados em formatos proprietários.

\section{Servidor de automação}

-WebBrowser

-> Diversas soluções para Linux, Mac, Windows..

-> Sem licenças ou softwares proprietários

-Cliente FTP

-> Diversas soluções para Linux, Mac, Windows.

-> Sem licenças ou softwares proprietários

\section{-Cliente E-Mail}

-> Diversas soluções para Linux, Mac, Windows.

-> Sem licenças ou softwares proprietários

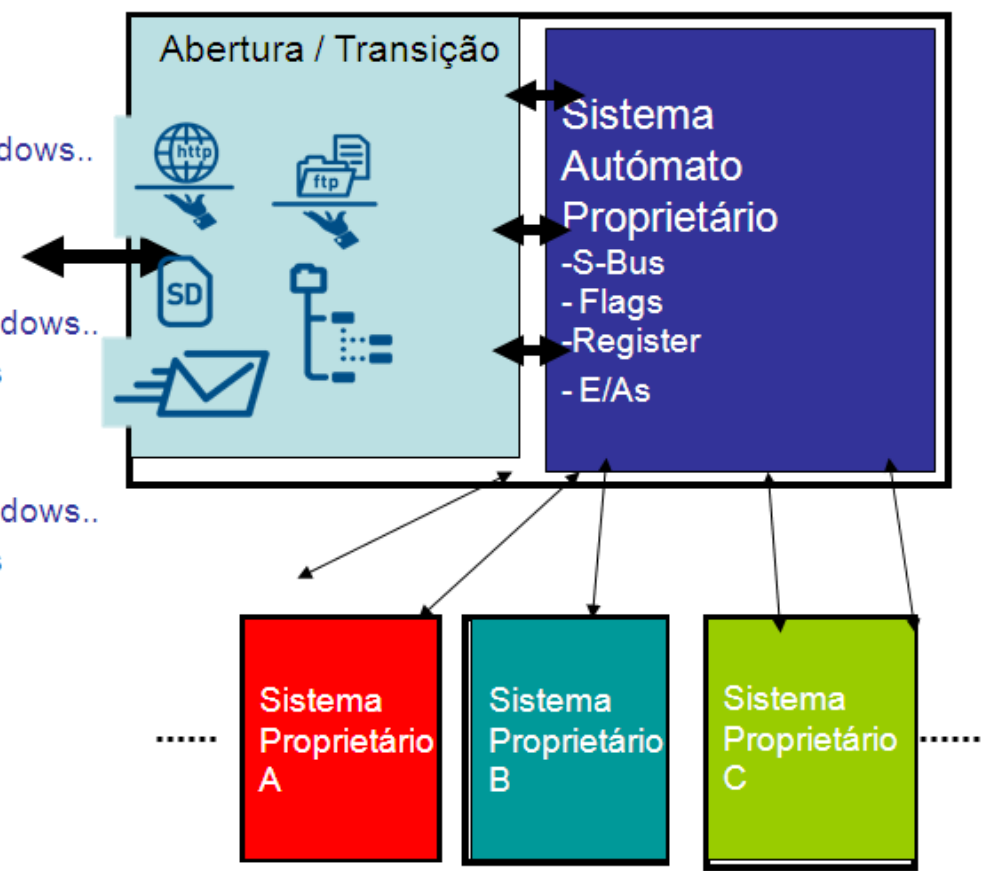




\section{ARTigo TÉCNICO}

2. Lean Automation - Otimizar, remodelar e expandir a GTC durante o tempo de vida da instalação

Normalmente, a solução de Gestão Técnica Centralizada adjudicada é aquela cujo investimento seja o mais reduzido possível, cumprindo minimamente os requisitos de controlo e de funcionamento exigidos em CE e definidos nas normas aplicáveis.

$\mathrm{Na}$ prática, isso significa que algumas funcionalidades e características, essenciais para a exploração e a manutenção da instalação ao longo dos anos seguintes, são minimizadas ou mesmo eliminadas de modo a tornar a solução mais barata. Só que, por norma, a maior percentagem de custos dá-se durante o ciclo de vida de um edifício e quase sempre acontece que o barato acaba por sair muito caro ao cliente final...

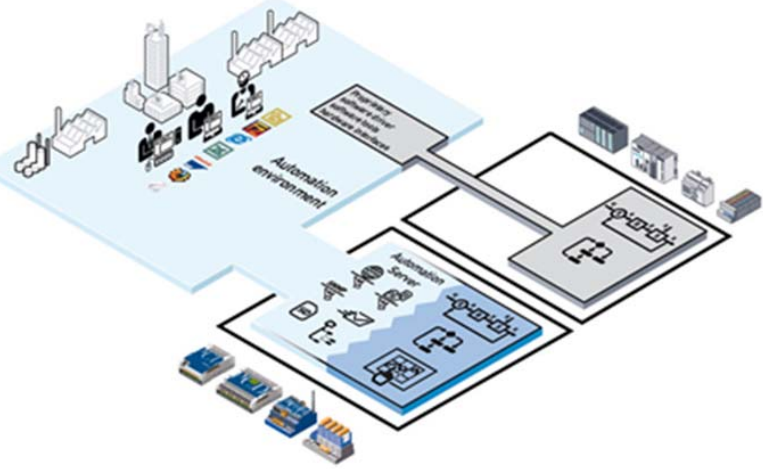

Antes - Importante: Custo inicial

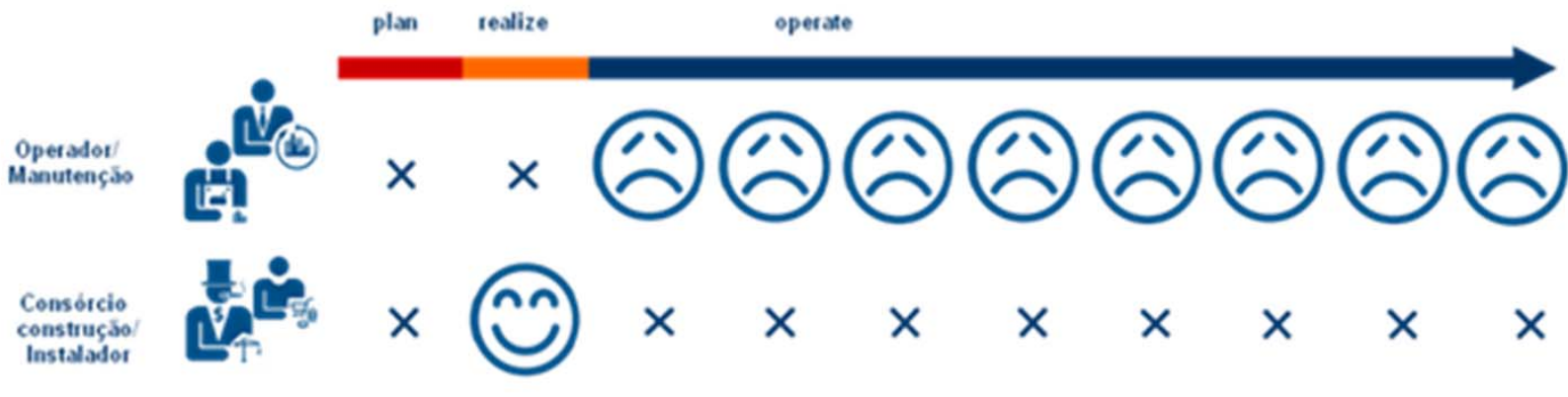

\section{Peace of Mind - Importante: Custo ao longo do tempo de vida da instalaçäo}

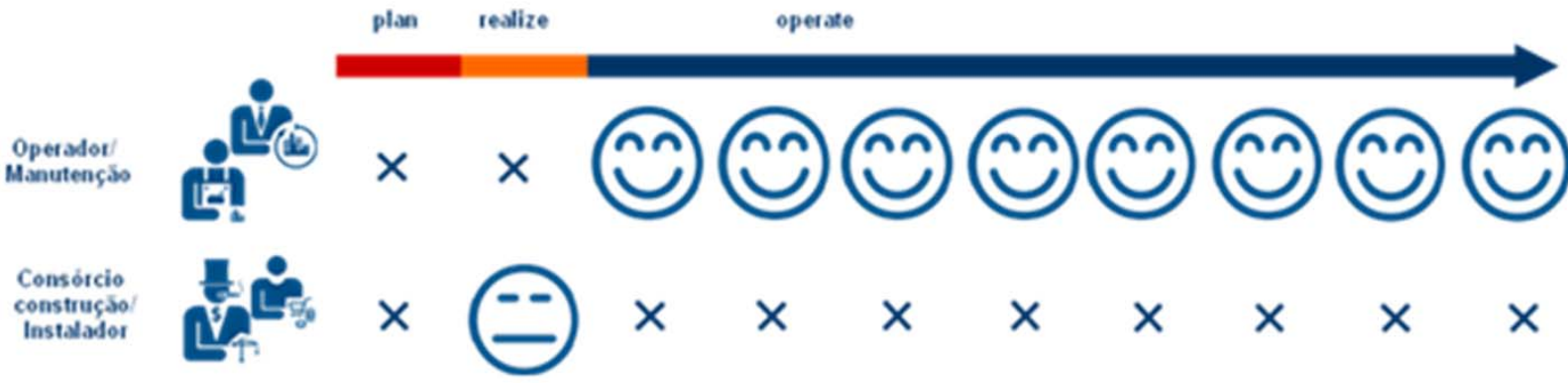


A aplicação do conceito Lean à GTC conduz a uma otimização da instalação com base na Cadeia de Valor: Projetista, Consórcio, Integrador da GTC, Fiscalização, Cliente Final e Responsáveis por Exploração e Manutenção.

Todos estes agentes deverão ter uma participação ativa no processo de decisão - no momento de planeamento e adjudicação - e melhoria - no momento do arranque, com a necessidade de otimização da instalação - , com vista a ter uma instalação que preencha os requisitos do consórcio de construção - Solução economicamente competitiva - e os requisitos do Cliente Final - Solução que acompanhe o tempo de vida da instalação.
De modo a conseguir-se este objetivo, a GTC deverá ser o mais aberta - integração de outras tecnologias/sistemas, quer sejam de automação como IT -, flexível - facilidade de remodelação e expansão futuras com custos reduzidos - e versátil - facilidade de adaptação às diversas circunstâncias quer no arranque da instalação como durante o tempo de vida do edifício.

A solução de GTC da Infocontrol vai ao encontro deste objetivo já que reúne todas as características atrás indicadas, tendo a Infocontrol já diversas referências em que este conceito foi decisivo no momento de adjudicação.

\section{Lean Automation :}

Remodelação, optimização e expansão fácil durante o tempo de vida da instalação!
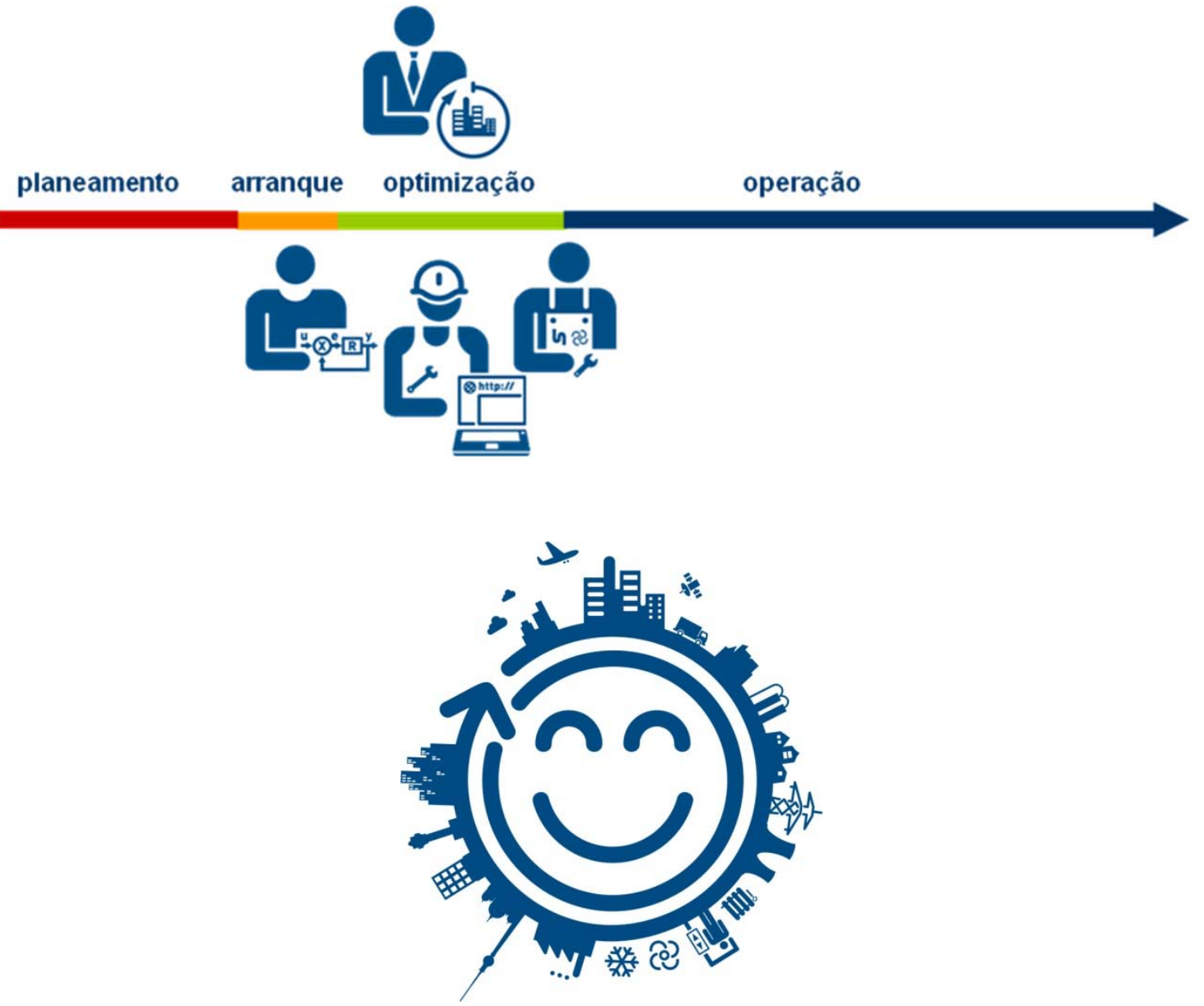